Vol. 1: (June.) 2012

\title{
Alvin Toffler: Knowledge, Technology and Change in Future Society
}

\author{
WAN FARIZA ALYATI WAN ZAKARIA ${ }^{1}$
}

\begin{abstract}
In this article, we attempt at analysing the thoughts of Alvin Toffler. Toffler is a prominent futurist and the proponent of the theory of 'The Third Wave society'. In his theory, Toffler has explicitly discussed the role of knowledge and technology in effecting changes and thus shaping the coming of the new type of society in the future.
\end{abstract}

Keywords: future studies, social change.

According to Krishan Kumar (2001: vi), the theory of future society has fascinated many Western scholars since long time, as he claims that:

Over the past quarter of a century there have been persistent claims that Western societies have entered a new era of their history. While still being undoubtedly industrial, they have undergone, it is suggested, such farreaching changes that they can no longer be considered under the old names and by means of the old theories. Western societies are now in various ways 'post-industrial': 'post-Fordist,' 'post-modern,' even 'post-historical'... Their theories concentrated largely on the move to a service economy and a 'knowledge society', and the social and political changes that could be expected to follow from this. Those theories are still with us, but they have joined by others with a more ambitious scope. In these newer theories we encounter claims that go beyond economics and politics to encompass western, and indeed world, civilization in their entirety. In the information and communication revolution, in the transformation of work and organization in the global economy, and in the crisis of political ideologies and cultural beliefs, these theories see the signs of a turning point in the evolution of modern societies.

It is evident that the futurists' social theories cannot be separated from the theories of social change, such as evolutionary, conflict, cyclical, functional, and technological. In fact, discourse on future has explicitly incorporated theories of social change purported by social theorists such as Karl Marx and Max Weber. ${ }^{2}$ Their analyses on classical industrialism and

\footnotetext{
${ }^{1}$ Wan Fariza Alyati Wan Zakaria, Ph.D., Senior Lecturer at Department of Theology and Philosophy, Faculty of Islamic Studies, Universiti Kebangsaan Malaysia, 43600 BANGI, Selangor, Malaysia, email: aufaa@ukm.edu.my.

2 Karl Marx proposed a theory of an ideal society in the form of communism and socialism as the final synthesis after capitalism in which the social struggle of the proletariats over the bourgeoisies has then led to radical changes in societies. Max Weber on the other hand, studied the dynamism of Protestant ethics which influenced the life of the pre-industrial Western societies and thereafter spread the seeds of capitalism and industrialism.
} 
the type of society inhabited by most westerners are still discussed in contemporary times in the form of post-industrialism. There are at least three different theories of postindustrialism - the information society, post-Fordism, and post-modernism, of which sometimes overlap one another.

The differences of these three theories are more on their emphasis, but there are also certain themes and figures recur in each theory, for instance the centrality of information technology which defines the information society idea, is also found in the other two theories. Such are the case of globalization, decentralization and diversity which, according to Kumar, feature prominently in all accounts of the new era. He concedes that “...the information society theories tend to adopt an optimistic, evolutionary approach that puts all the emphasis on major new clusters of technological innovations. The information revolution is the latest, and by so much the most progressive, step in the sequence of changes that have transformed human society since earliest times - such can be found in Alvin Toffler's conviction on history as a 'succession of rolling waves of change" (Kumar 2001: 36-7; Toffler 1981: 13).

Indeed, as far as Futures Studies is concerned, the theories of social futurism whatever the names - are therefore significant. In other words, these theories are the "grand theories" of humanity; and the theory of super- or post-industrial society in fact is a unique Western analysis to study the phenomenon of modernity and how it will continue to define and shape the Western society in particular and the global society in general in the future.

\section{Alvin Toffler: A Biographical Sketch}

Alvin Toffler was born in 3 October 1928 in New York. During his adolescence age, he was a Marxist activist, as he recalled “...when I was a Marxist during my late teens and early twenties - now more than a quarter of a century age - I, like many young people, thought I had all the answers. I soon learned that my 'answers' were partial, one-sided, and obsolete" (Toffler 1981: 6). In light of his exposure to Marxist socialism which was a social utopia of an ideal society, he developed a special concern about future.

In his early adulthood, Toffler worked as an associate editor of Fortune magazine in Washington, and later in the factories (Toffler 1981: 6). He finally found his contentment as a writer and since his bestseller Future Shock published in 1970, he had written more than 10 books, many of them with Heidi, his wife. Among his early books were The Adaptive Corporation, Preview and Premises, The Eco-spasm Resort, The Culture Consumers and Learning of Tomorrow. He is renowned through his famous trilogy - Future Shock (1971), The Third Wave (1981) and Powershift (1991). His latest work, Revolutionary Wealth (2006), continues his thematical work on the nature of the Third Wave society or the information society.

Although his works have been considered to be more of 'pop sociology' and of little substance by some critics, his thoughts have been widely accepted and his books are globally circulated with millions of copies. Apart from that, he has been appointed to various academic positions such as Visiting Professor at the Cornell University and Visiting Scholar at the Russell Sage Foundation. His intellectual works had been recognized through various prestigious awards such as Le Prix du Mueller Livrev Estranger of France and the Golden Key Award of China. 


\section{Knowledge, Technology and Change in Future Society}

Alvin Toffler sets the framework of his analyses on the stages of human development by studying changes and the underlying forces that brought these changes and their impact on human life and experience. In his bestseller, The Third Wave, Toffler argues that these changes are in fact parts of a revolutionary process of what he metaphorically termed as colliding "waves" of change in creating a new civilization that "...challenges all our old assumptions" (Toffler 1981: 2). In describing the process of social change experienced by human society, Toffler argues that every civilization has its own atmospheres: 1 , Technosphere - an energy base - production system - distribution system; 2, Socio-sphere - interrelated social institutions; 3, Info-sphere - channels of communication; 4, Power-sphere, including relationships with outside world - exploitative, symbiotic, militant or pacific; 5, Super ideology - powerful cultural assumptions that structure its view of reality and justify its operation (Toffler \& Toffler 2006: 349-50).

According to this waves theory and the structure of their atmospheres, Toffler divides human societies into three distinct categories: ${ }^{3}$ the First Wave is the society after agrarian revolution and replaced the first hunter-gatherer cultures; the Second Wave society "...is industrial and based on mass production, mass distribution, mass consumption, mass education, mass media, mass recreation, mass entertainment, and weapons of mass destruction...combine[d]...with standardization, centralization, concentration, and synchronization, and...a style of organization we call bureaucracy".4

According to Toffler, all these six principles grew out from basic cleavage between producer and consumer and the ever expanding role of the market (Toffler 1981: 46-56). The Third Wave society therefore, is regarded by Toffler as the new breed in formation therefore it is still in its embryonic stage, not yet to be realized but could be recognized

${ }^{3}$ He elucidates: "For the purpose of this book we shall consider the First Wave era to have begun sometime around 8000 B.C. and to have dominated the earth unchallenged until sometime around A.D 1650-1750. From this moment on, the First Wave lost momentum as the Second Wave picked up steam. Industrial civilization, the product of the Second Wave, then dominated the planet in its turn until it, too, crested. This latest historical turning point arrived in the United States during the decade beginning about 1955 - the decade that saw white-collar and service workers outnumber blue-collar workers for the first time. This was the same decade that saw the widespread introduction of the computer, commercial jet travel, the birth control pill, and many other highimpact innovations. It was precisely during this decade that the Third Wave began to gather its force in the United States. Since then it has arrived - at slightly different dates - in most of the other industrial nations, including Britain, France, Sweden, Germany, The Soviet Union, and Japan" (Toffler 1971: 14).

4 In details, he described the principles of the Second Wave civilization as follow: 1, Standardization - identical products (hardware); business procedures and management (software); curricula (for schools), accreditation, policies, admission procedures; job - pay scale; one-price policy. 2, Specialization - diversity in work sphere; divisions of labour doing different type of jobs; fragmentation, limited skills and knowledge; rise of professionalization which he claimed as refined division of labour claiming to monopolize esoteric knowledge. 3, Synchronization - concerned with how people dealt with time which equals money; the beat of heart to the beat of machine; punctuality became necessity; 9-5 job time. 4, Concentration - to certain/specific place, person etc; energy; population; work (factories); criminals (prison); students (school); corporation/industries (trust and monopoly). 5, Maximization - "the addiction to bigness"; big became synonymous with efficient/efficiency; maximizing "growth" to increase GNP. 6, Centralization - in business, management, politics, government, power, banking (Toffler 1971: 87-99). 
through some of its characteristics. The characteristics of the Third Wave civilizations, he asserts, could be seen in many categories - the new image of nature; the new idea of progress, time and space; new causality and holism.

In terms of its image of nature, the Third Wave society contains symbiosis, harmony, recycle and renewable energy and the idea that nature must be protected. In terms of progress, it no longer measured by material or technology; in terms of time, it is relative and space, global and local at the same time. In terms of rule of causality, equal attention is given to both negative and positive feedback and mutual interacting forces. Above all, it values the concept of holism - i.e systems approach, more integrative way of looking at problems and revolt against overspecialization, appreciative to multi-disciplinarian approach and where analysis and synthesis approaches are combined (Toffler 1981: 299-306).

The central subject of his theory of future society is how change would affect people when their entire society abruptly transforms itself into something new and unexpected. He also stresses on the relationship between power triad - knowledge, violence (force) and wealth (money); muscle, money and mind, which he claims as the quantity versus quality of power; those who understand "quality" will gain a strategic edge. Therefore, Toffler regards knowledge as the highest quality power because it implies efficiency and used to punish, reward, persuade and transform. As the source of the highest quality power, knowledge is also the most important ingredient of force and wealth. With power, he further argues, "we can always generate more...we may never reach ultimate knowledge about anything, but we can always take one step closer to a rounded understanding of any phenomenon. Knowledge, in principle at least, is infinitely expandable" (Toffler 1991: xvii, 14-17 \& 19).

In an overstated stress on the power of knowledge in the future society, Toffler says that "...today, in the fast-changing, affluent nations, despite all inequities of income and wealth, the coming struggle for power will increasingly turn into a struggle over the distribution of and access to knowledge. This is why, unless we understand how and to whom knowledge flows, we can neither protect ourselves against the abuse of power nor create the better, more democratic society that tomorrow's technologies promise. The control of knowledge is the crux of tomorrow's worldwide struggle for power in every human institution" (Toffler 1991: 20).

As knowledge becomes the most powerful tool in the future society, it will produce more changes. This is how the future, according to Toffler, invades our lives (Toffler 1981: 1). The changes in process, according to his analysis, would be evidently perceived in at least three significant parts in modern society: rapid urbanization, human's consumption of energy and the acceleration of economic growth. Knowledge therefore, is the fuel for change, whereas technology is its engine. The pace of changes that resulted from knowledge and technology has created what Toffler called as 'transience' in which everything is temporary - in fact he argues for the death of permanence (Toffler 1981: 1). The nature of this new super-industrial revolution therefore, he believes, lies in transiency, diversity and novelty. Thus, he urged the need for both individuals and societies to learn ways to adapt to and manage the sources of over-rapid change by bringing technological innovation under some sort of collective control (Toffler 1981: 428).

The type of collective control over technological innovation, he emphasizes, must “. . . involves the conscious regulation of scientific advance" (Toffler 1981: 428). For this reason, what needed, he believes, are more sophisticated criteria for selection of technologies (Toffler 1971: 433). In other words, technologies must undergo through strict selection procedures to evaluate the purpose of their innovations and applications in the society. Serious efforts are also needed to be devoted to anticipating the consequences of 
technological developments. Toffler firmly believes in managing technology by regulating its advancement to prevent secondary social effects resulted from technology through the process of anticipating them in advance, estimating their nature, strength and timing and if necessary, to impede the new technology that would damage the societies in long term. In short, he affirms that technology cannot be tolerated to charge the society (Toffler 1971: 438). Sealing the solution for technological regulation, Toffler says that what is needed is 'a machinery for screening machines' through the 'environmental screening' procedures which are carried out by the 'technology ombudsman' for protecting society from unseemly effects (Toffler 1971: 440). This means creating new political institutions for guaranteeing that the questions of environment are investigated and for promoting or discouraging, even banning certain proposed technologies.

Conclusively, the idea of change, or to use his verbose term, the Gospel of change, is the real message that America sends to the rest of the world, and "...this gospel doesn't specify whether change will be good or bad...The Gospel of change is most dangerous to established institutions and order precisely because it is not inherently right-wing or leftwing, democratic or authoritarian. Its implicit meta-message is that all our societies, all our current ways of life and even our beliefs are inherently temporary" (Toffler \& Toffler 2006: 209). The self-claim value-free changes that precipitated in today's world engender the sense of transiency - the temporality of experience and being that becomes one of the characteristics of the postmodern society.

Toffler's ideas on future have created public attention on futures-related issues including the complexity of transformational processes and the rate of change and its related consequences. However, Toffler's overemphasis on the impact of 'change' as "a wholly external force" has neglected the more important fact that change works through what Richard A. Slaughter called as "specific social formations and the structures and processes that maintain their interests." He also criticized the practicality of Toffler's proposal as his analysis apparently did not embark on the underlying basis of technological advancement that creates such chaotic consequences - the worldviews, presuppositions and ideologies that he argued as deeply embedded in the current global system Slaughter argues that Toffler's diagnosis on the 'disease' of future shock had also overemphasized the response of "these decontextualised and 'shocked' individuals" and at the same time disregarded the rest of the general public (or in Slaughter word, social entities) that "...were (and remain) complicit in generating and sustaining 'change'” (Slaughter 2002: 4). In his explicit criticism on Toffler's approach on change, he maintains that:

... this was a disempowering approach that displaced autonomy from individuals and groups into poorly defined and shadowy social locations that could neither be readily located nor challenged. Linked with this is the way that Toffler ascribed the prime responsibility for 'rapid change' to 'technology' - not to the agencies and powers that have the ability to define, focus, develop, market and apply it. The effect was mystificatory in effect, though not, I am sure, in intent. While Toffler sought to encourage 'social futurism' and 'anticipatory democracy' he did so in a way that completely overlooked the difficulties people face in (a) understanding and (b) attempting to intervene in their historical context. In summary, the Future Shock thesis can be seen as an expression of a journalistic view of macrochange from a very particular viewpoint in space and time. It foregrounds the habits of perception that are characteristic of that time and attempts to 
universalise them. As noted, this framework certainly provided some useful suggestions for possible ways forward. But as an interpretive agenda it was unworkable in practice. Conspicuously lacking were ways of understanding, and coming to grips with, other dysfunctional imbalances in culture. 'Change' is only one of them. Meaninglessness, lack of purpose, hypermaterialism, technological narcissism and spiritual hunger are a few of the others that might be encompassed within a wider view. But 'Future Shock' was silent upon them all (Slaughter 2002: 4-5).

As far as future shock is concerned, Slaughter considers Toffler's "vivid social imagination" had surpassed its practical grasp, lacked of means and needed a lot more work before they could be put into practice. A greater concern for him, was Toffler's journalistic inclination on "the outer empirical world (facts, trends, change processes)" and thus missed "the inner interpretive one (worldviews, paradigms, social interests)" (Slaughter 2002: 5). The lack of interpretive analysis hindered the understanding of how to transfer futures proposals from their idealistic forms into social action, and this, according to him, is what lack in Toffler, and indeed many other futurists. He also argues that "...while Toffler's research had provided him with numerous indicators and examples from which emerged a rich store of futures-related ideas and proposals, most of those reading his work were unable to translate his proposals into action for one simple reason. They did not have the means to cross this symbolic gulf. To move from ideas to action in fact requires progress though several 'layers of capability' which had not yet been described at that time" (Slaughter 2002: 5). Toffler's concern over technological assessment is principally right but Slaughter advances his criticisms on Toffler's shallow analysis of “...the worldviews, presuppositions, ideologies and embedded interests that were driving (and continue to drive) the global system has put him in a weak position to call into question the apparent inevitability of technological advance or to propose means of dealing with it at a constitutive level. Hence his well-meaning suggestions were, and are, outstripped by vastly more powerful forces" (Slaughter 2002: 6).

Overall, Toffler has demonstrated that knowledge and technology are the two powerful determinants in facilitating changes in society, and thus bring the society to an unprecedented process of transformations to a new type of order he termed as "the Third Wave society". And it is at this point that relates Toffler's idea of the super-industrial society in the form of the Third Wave society with the theory of future society.

\section{Discussion}

The schematic future society in the notion of Third Wave civilization values information and knowledge as the determinant feature. Toffler's analysis on the information society however, dismisses the rationalization process of the Third Wave societies that underlined the deeper and fundamental process foregoing the creation of a new breed. Rather, he was more concern with the question of how knowledge transforms power relation, and also how it facilitates further invention of new technology. This, in his view, led changes in the nature of knowledge to decentralization of knowledge that frees the mind from the monopoly of knowledge in the hand of the authority. Knowledge, for Toffler, is thus a power question and a political issue (Toffler \& Toffler 2006: 145). The democratization of knowledge through the advancement in communication technology also brings a non-hierarchical communication networks (Toffler \& Toffler 2006: 173). It is a question about the 
relationships between knowledge and power in society and the link between how people organize their concepts and how they organized their institutions (Toffler \& Toffler 2006: 174).

In Toffler, as we can see, the role of knowledge and information revolves to become the bargaining power. He seems to agree on the point that developments in information and communications technologies will ensure a freer future for the 'information society'. This pure optimist view on the significance of information as intrinsically beneficial is a typical evolutionist-historicist view of future. The underlying assumption is that greater flow of information and communication will result in increased knowledge, creativity and understanding among people.

Suspicions and criticisms on the naïve judgment on 'information society' scenarios sketched by Toffler were raised on the basis that information and knowledge are represented as important beneficial and progressive social force. One of the arguments against the notion of 'information society' that characterized the Third Wave civilization suggests that knowledge/information has long been a key component of regulation in the modern nation state and in capitalist economies; 5 it is in fact, not a uniquely post-industrial feature or the Third Wave civilization as such. Thus, the lofty role of knowledge/information in the future society has been overestimated in Toffler in his theory of information society. Indeed, knowledge has been the hallmark in any advanced societies and civilizations since long time, whether in the past or in the present. Ibn Khaldūn's analysis on the transformational process of the badawa society to the state of hadāra, with the emphasis on the role of knowledge as the main characteristic of the hadāra state depicts such an instance.

Some see Toffler as a visionary whose writings can help foretell the future and whose interpretations of current trends can help make the future a reality. Others see his writings as superficial "pop sociology" that offers little of substance. These critics accuse him of substituting glib clichés and jargon - "premature arrival of the future," "massive adaptational breakdown," "social future assemblies," and so on - for serious thought, and they take him to task for his shallow (or nonexistent) reading of history. The image of the future society in Toffler's imagination is a paradise - a "practopian future" to use his own term - for industrialism and its twin children, capitalism (in the form of service economy) and technology (in which the mastery of theoretical/scientific knowledge/information is the requisite). The first basis as disscussed on the rationalization process of knowledge and system demonstrated that the unlimited expansion of rational mastery has become the basic criterion in producing industrialism.

Conclusively, this techno-utopianism assumes the neutrality of technological innovation and its endorsement of a technologically determinist view of history (Robins \& Webster 1999: 84-5). Our analysis shows that in terms of technology, Toffler works within the mainstream of the Western futurists' scholarship that inclines towards technological determinism. He regards technology as one of the determinant factors in social change that caused colossal transformation in the setup of the contemporary society and eventually extrapolate the present situation into a single direction in the future - the techno-utopian future. The Western techno-culture has been fundamental to this industrialization project since the Enlightenment. Following the same lineal trend, this techno-culture of industrialization project will continue in the form of the Third Wave and post-industrial society, only in more sophisticated varieties thanks to the advance of technology.

\footnotetext{
${ }^{5}$ Interesting criticism on this can be found in Kevin Robins \& Frank Webster (1999: 82-85).
} 


\section{References}

Kumar, Krishan. 2001. From Post-Industrial to Post-Modern Society: New Theories of the Contemporary World. Oxford: Blackwell.

Robins, Kevin \& Webster, Frank (eds.). 1999. Times of the Technoculture: From the Information Society to the Virtual Life. London: Routledge.

Slaughter, Richard A. 2002. Future Shock Reassessed. http://www.metafuture. org/articlesbycolleagues/RichardSlaughter/futureshock.htm. Accessed on 08 May 2012.

Toffler, Alvin. 1971. Future Shock. (Bantam edition). New York: Bantam Books.

Toffler, Alvin. 1981. The Third Wave. New York : Bantam Books.

Toffler, Alvin. 1991. Powershift: Knowledge, Wealth, and Violence at the Edge of the 21 st Century. New York: Bantam Books.

Toffler, Alvin \& Toffler, Heidi. 2006. Revolutionary Wealth. New York: Alfred A. Knopf. 